Supplement of Atmos. Chem. Phys., 21, 11505-11518, 2021

https://doi.org/10.5194/acp-21-11505-2021-supplement

(c) Author(s) 2021. CC BY 4.0 License.

(c) (1)

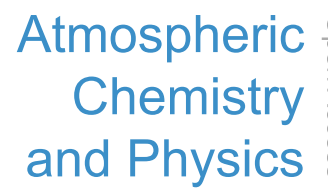

Supplement of

\title{
Unexplored volatile organic compound emitted from petrochemical facilities: implications for ozone production and atmospheric chemistry
}

Chinmoy Sarkar et al.

Correspondence to: Chinmoy Sarkar (chinmoysarkar8@gmail.com), Jin-Soo Park (airchemi@korea.kr), and Saewung Kim (saewung.kim@uci.edu)

The copyright of individual parts of the supplement might differ from the article licence. 
Supplementary information for "Unexplored VOC emitted from petrochemical facilities: implications for ozone production and atmospheric chemistry" by C. Sarkar et al., 2020:

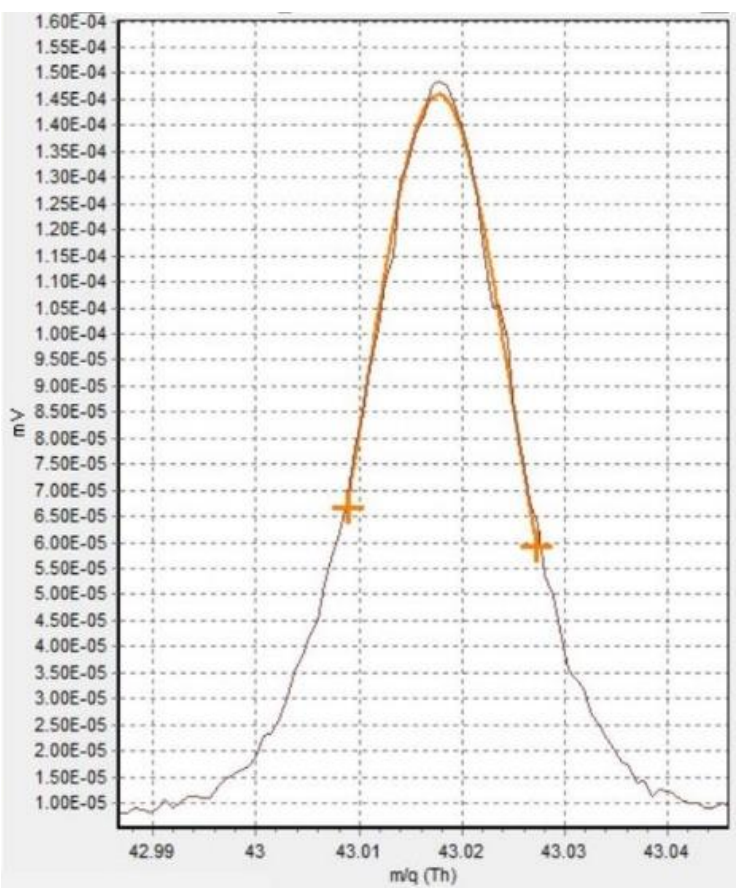

Figure S1. Illustrative mass spectra (30 second average) of ketene (ethenone) obtained at 09:56 Local Time (LT) during 29 May morning flight

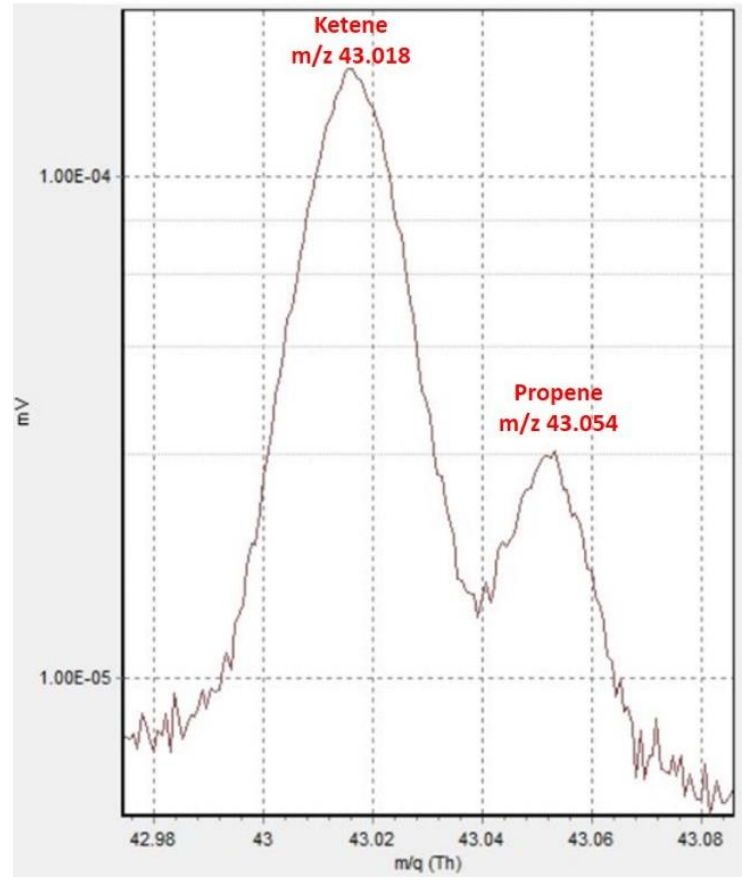

Figure S2. Illustrative mass spectra (30 second average) of showing the separation of ketene (m/z 43.018) and propene ( $\mathrm{m} / \mathrm{z}$ 43.054) obtained during 29 May morning flight 


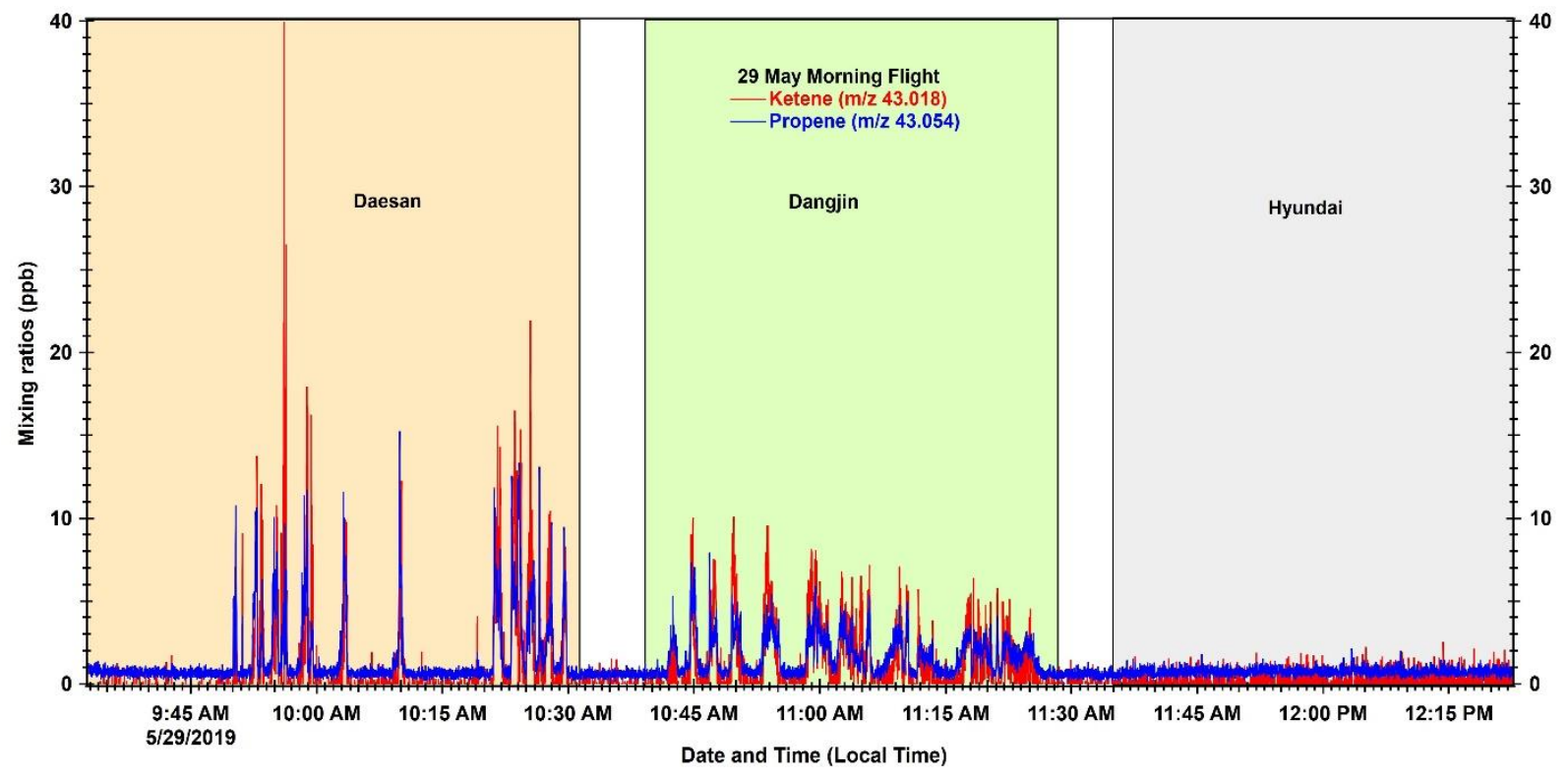

Figure S3. Timeseries plot of the corrected ketene measured at $\mathrm{m} / \mathrm{z}=43.018$ (in red) and propene measured at $\mathrm{m} / \mathrm{z}=43.054$ (in blue) during the research flight conducted on 29 May morning

\section{Fall 2019 Timeseries:}

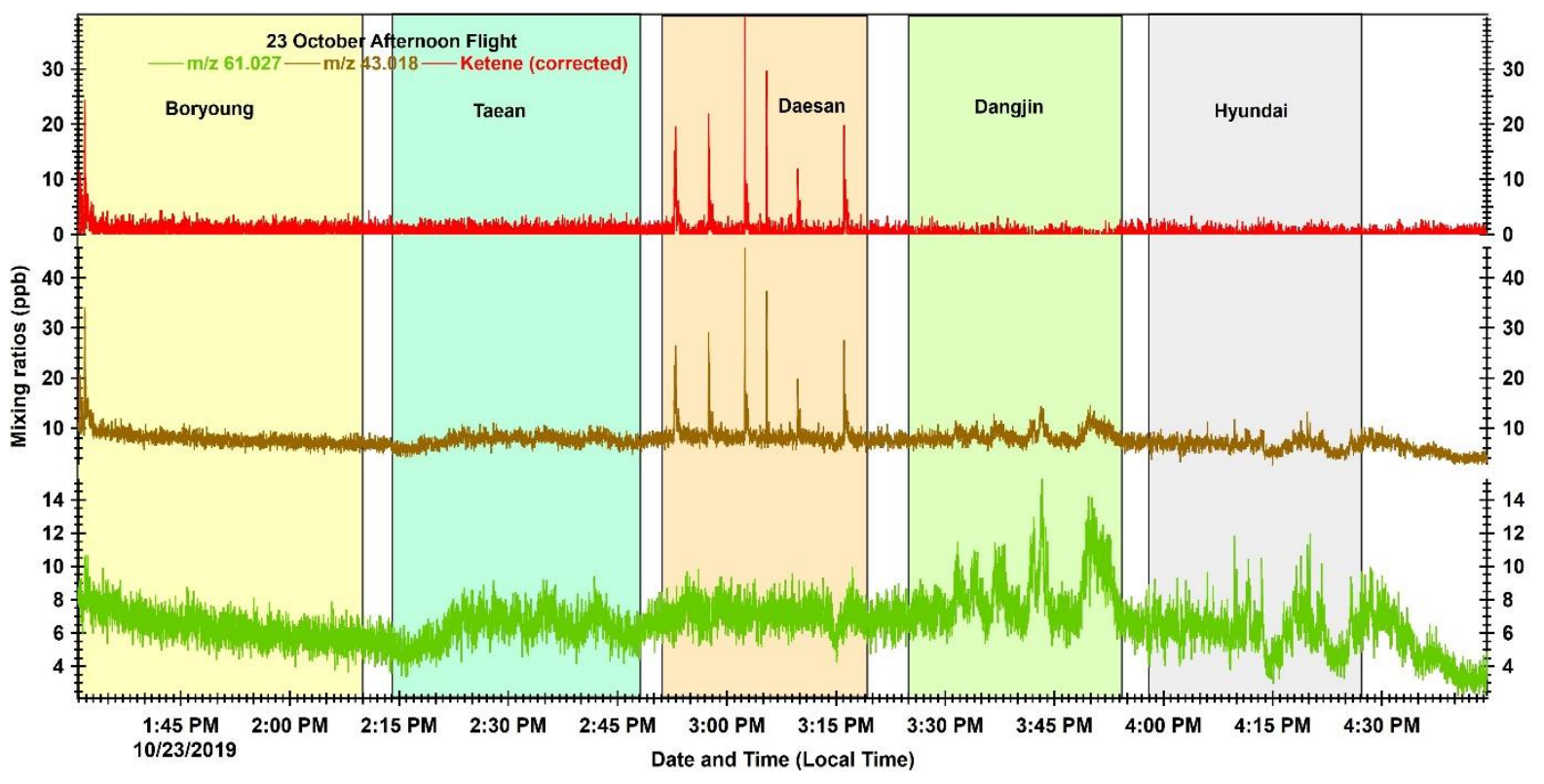



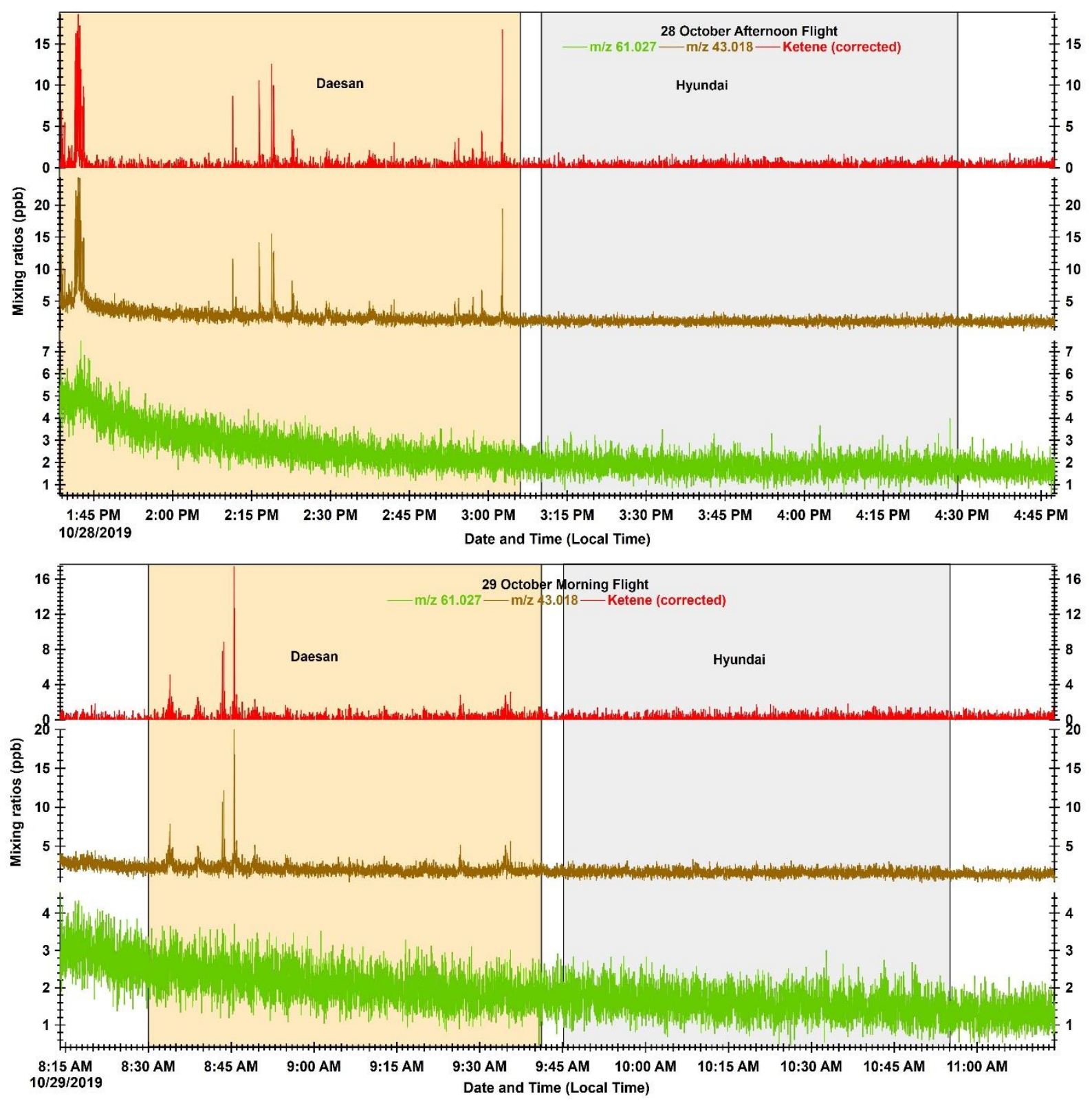

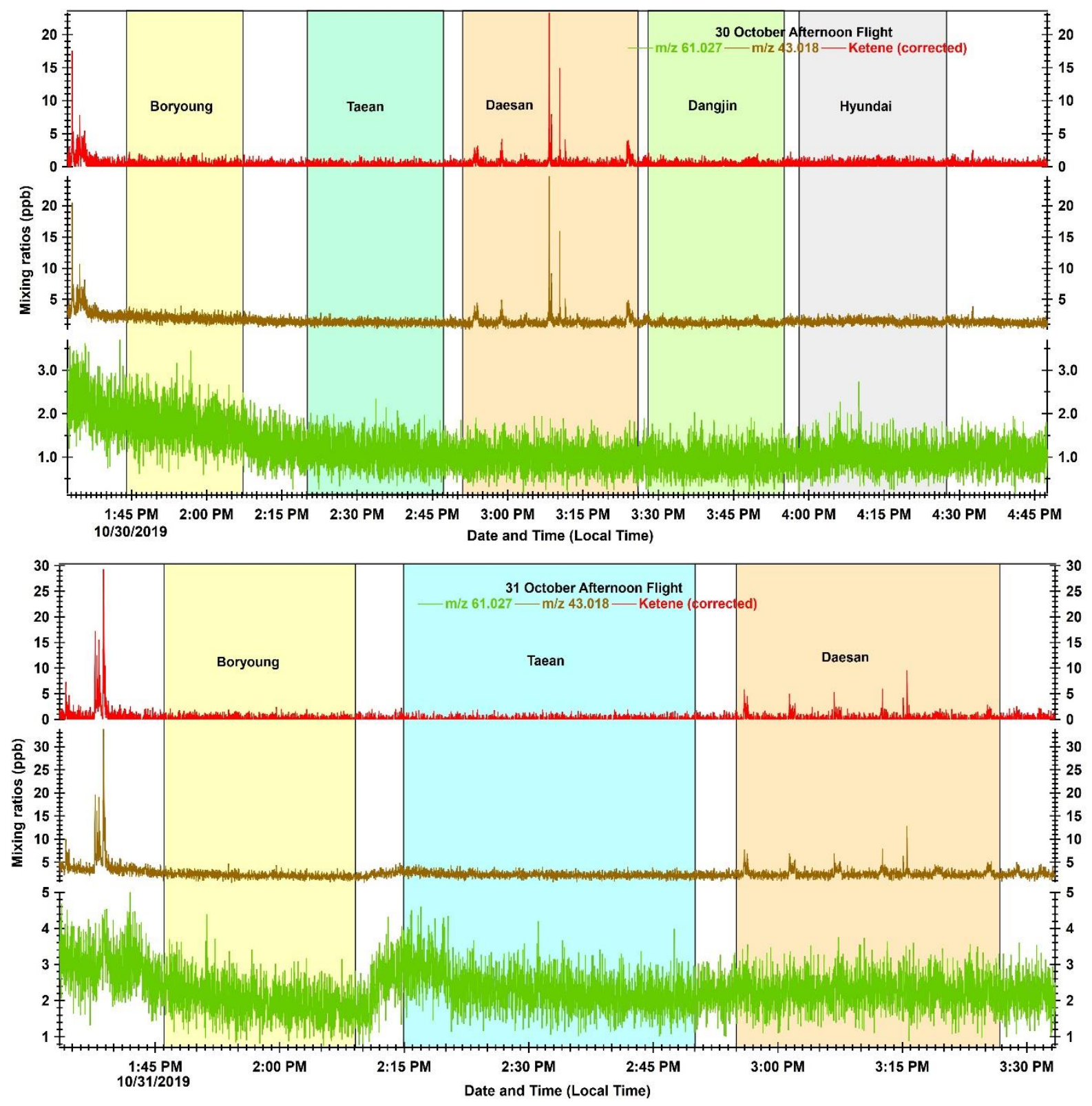

Figure S4. Timeseries profiles for mixing ratios (1 Hz resolution) of acetic acid and glycolaldehyde parent ion $(\mathrm{m} / \mathrm{z}=61.027)$, ketene fragment $(\mathrm{m} / \mathrm{z}=43.018)$ and corrected ketene (corrected for $\mathrm{m} / \mathrm{z} 61.027$ fragmentation) during five research flights conducted on October 2019 (fall season). The light yellow, violet, cyan, green and pink shaded areas represent the duration for which flights were flying over Boryoung, Hyundai, Taean, Dangjin and Daesan, respectively 

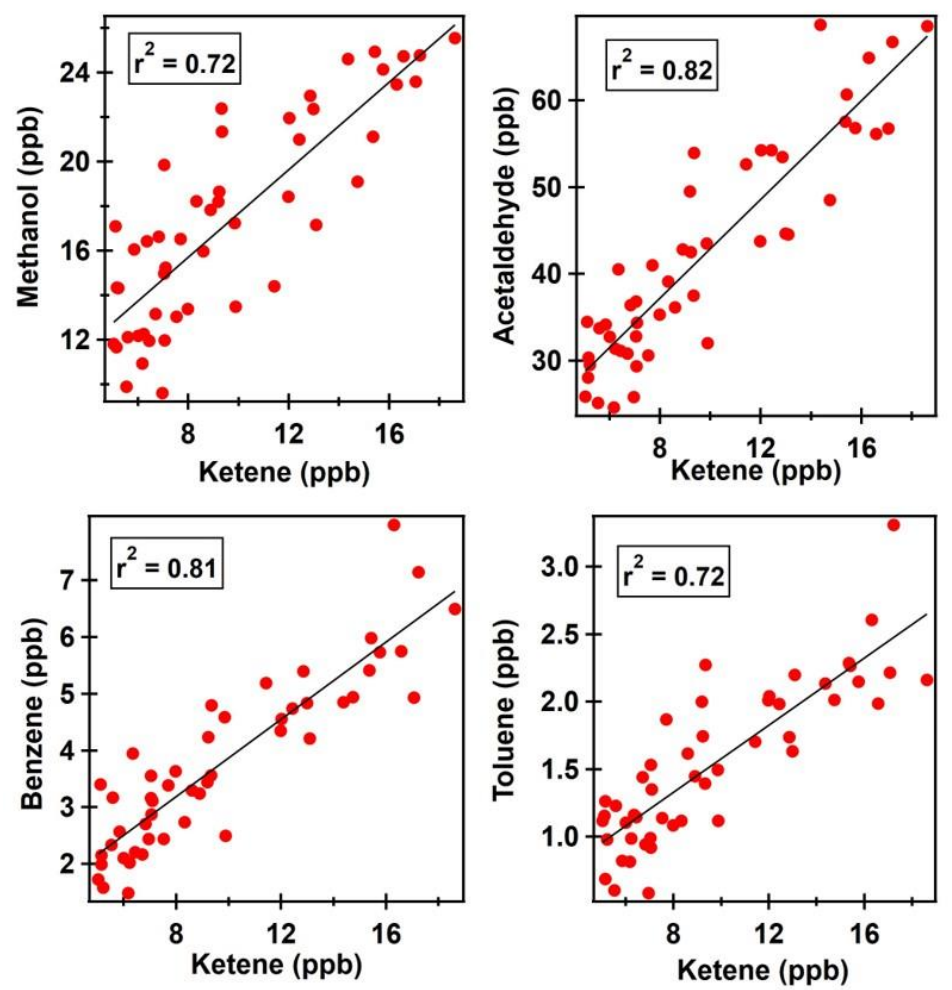

Figure S5. Correlation for the peak values of ketene with methanol, acetaldehyde, benzene and toluene (using $1 \mathrm{~Hz}$ data) over Daesan petrochemical facility during 28 October afternoon flight

Table S1. Sensitivity factors and limit of detections (LOD) for methanol, acetaldehyde, benzene and toluene

\begin{tabular}{cccc}
\hline VOCs & $\mathbf{m} / \mathbf{z}$ & $\begin{array}{c}\text { Sensitivity factor } \\
(\mathbf{n c p s} / \mathbf{p p b})\end{array}$ & $\begin{array}{c}\text { Limit of detection } \\
\text { (LOD) in } \mathbf{p p b}\end{array}$ \\
\hline Methanol & 33.034 & 14.86 & 2.27 \\
Acetaldehyde & 45.033 & 30.27 & 2.30 \\
Benzene & 79.054 & 25.90 & 0.10 \\
Toluene & 93.070 & 30.61 & 0.11 \\
\hline
\end{tabular}

Table S2. Emission rates of VOCs measured over Daesan petrochemical facility. Values represent the emission rate going out of the screen

\begin{tabular}{|c|c|c|c|c|}
\hline Research Flights & $\begin{array}{l}\text { Ketene } \\
\left(\mathrm{kg} \mathrm{h}^{-1}\right)\end{array}$ & $\begin{array}{l}\text { Benzene } \\
\left(\mathbf{k g ~ h}^{-1}\right)\end{array}$ & $\begin{array}{l}\text { Acetaldehyde } \\
\left(\mathrm{kg} \mathrm{h}^{-1}\right)\end{array}$ & $\begin{array}{l}\text { Toluene } \\
\left(\mathbf{k g ~ h}^{-1}\right)\end{array}$ \\
\hline \multicolumn{5}{|l|}{ Summer 2019: } \\
\hline 29 May Morning & 354 & 991 & 1883 & 363 \\
\hline \multicolumn{5}{|l|}{ Fall 2019: } \\
\hline 23 October Afternoon & 337 & 252 & 786 & 487 \\
\hline 28 October Afternoon & 353 & 651 & 2145 & 191 \\
\hline 29 October Morning & 40 & 294 & 1026 & 131 \\
\hline 30 October Afternoon & 112 & 237 & 604 & 117 \\
\hline
\end{tabular}


Table S3. Parameters used in equation (8) to generate the Gaussian plumes for each date.

\begin{tabular}{lllllll}
\hline Fig. S7 & Date & $I$ & $S_{o, i}(\mathrm{~m})$ & $z_{o, i}(\mathrm{~m})$ & $\sigma_{s, i}(\mathrm{~m})$ & $\sigma_{z, i}(\mathrm{~m})$ \\
\hline a) & May 29, 2019 & 1 & 3750 & 115 & 800 & 400 \\
& & 2 & 6800 & 115 & 800 & 400 \\
c) & Oct. 28, 2019 & 1 & 11200 & 115 & 800 & 400 \\
\hline
\end{tabular}

